\title{
Correlation Between Maternal Obesity, Progress of Labour and Risk of Caesarean Delivery in a Cohort of Nigerian Parturients
}

\author{
Ajen Stephen Anzaku ${ }^{1,}$, Adelaiye Samuel Makanjuola ${ }^{1}$, Yakubu Emmanuel Nyam", \\ Utoo Bernard Terkimbi ${ }^{2}$, Edem Bassey Edet $^{3}$ \\ ${ }^{1}$ Department of Obstetrics and Gynaecology, College of Medicine and Health Sciences, Bingham University, Jos Campus, Jos, Nigeria \\ ${ }^{2}$ Department of Obstetrics and Gynaecology, Benue State University Teaching Hospital, Makurdi, Nigeria \\ ${ }^{3}$ Department of Anaesthesia, Federal Medical Centre, Makurdi, Nigeria
}

\section{Email addresses:}

steveanzaku@gmail.com (Anzaku A. S.), samueladelaiye@yahoo.com (Adelaiye S. M.), emayaks75@yahoo.com (Yakubu E. N.), bernardutoo@yahoo.com (Utoo B. T.),dredemb@gmail.com (Edem B. E.)

\section{To cite this article:}

Ajen Stephen Anzaku, Adelaiye Samuel Makanjuola, Yakubu Emmanuel Nyam, Utoo Bernard Terkimbi, Edem Bassey Edet. Correlation Between Maternal Obesity, Progress of Labour and Risk of Caesarean Delivery in a Cohort of Nigerian Parturients. Journal of Gynecology and Obstetrics. Vol. 3, No. 3, 2015, pp. 61-65. doi: 10.11648/j.jgo.20150303.14

\begin{abstract}
Background: Maternal obesity is associated with adverse obstetric outcomes including labour complications. This study aimed at assessing the relationship between maternal obesity and course of first stage of labour and risk of caesarean delivery among women in active first stage of labour. Methods: This retrospective cohort study was a secondary analysis of data collected to assess the impacts of maternal obesity on pregnancy outcomes in a Nigerian obstetric population. We compared progress of labour and risk of caesarean delivery in 170 obese [Body mass index $\left(B M I=\geq 30 \mathrm{Kg} / \mathrm{m}^{2}\right)$ ] and 170 normal weight women $\left(\mathrm{BMI}=18.5-24.9 \mathrm{Kg} / \mathrm{m}^{2}\right)$ who were in spontaneous labour at term. They were matched for age and parity and exclusion criteria included women with height less than 1.52 metres, medical disorders, previous caesarean section, those that had augmentation of labour and infant weight $>4.0 \mathrm{Kg}$. Statistical analysis was done using SPSS version 16 (SPSS Inc., Chicago, IL, USA). $\mathrm{P}<0.05$ was considered significant. Results: Mean age and parity of the women were $30.6 \pm 4.8$ years and $1.9 \pm 1.6$ respectively. There was no significant difference between mean cervical dilatation at presentation between the two study groups ( $4.9 \pm 1.8$ versus $5.0 \pm 1.7, \mathrm{P}=0.64)$. Cervical dilatation rate per hour was significantly slower in obese group compared to the controls $(0.87 \pm 0.4$ versus $1.2 \pm 0.5 \mathrm{~cm} / \mathrm{hr}, \mathrm{P}=0.001)$. The mean duration of labour was the same in both groups $(7.5 \pm 3.9$ versus $6.2 \pm 3.4$ hours, $\mathrm{P}=0.57$ ). Caesarean section rate increased from $8.8 \%$ in the controls to $23.5 \%$ among obese women. Obese women had three times higher risk of caesarean delivery compared to the controls $(\mathrm{P}=0.002$, OR 3.2, 95\% CI $1.15-8.62)$ and this was mainly due to failure to progress in labour $(\mathrm{P}=0.03)$. Conclusion: Among women in active phase of labour, maternal obesity was associated with slower rate of cervical dilatation and increased risk of caesarean delivery.
\end{abstract}

Keywords: Maternal Obesity, Progress of Labour, Caesarean Delivery, Parturient, Nigeria

\section{Introduction}

Maternal obesity is a known risk factor for adverse pregnancy outcomes [1 - 4]. Reports suggest that its prevalence is increasing among women of reproductive age in both developed and developing countries [5-7]. This trend of obesity among women requires healthcare providers to understand the implications and consequences of increased BMI to both the pregnant woman and the fetus. Prominent among the adverse pregnancy outcomes associated with obesity is increased risk of caesarean delivery $[1,8,9]$. The reasons for this high risk of caesarean section are however not clearly elucidated. This has been suggested to be due to higher risk of pregnancy complications such as hypertension and diabetes often associated with obesity [10] as they predispose to the need for operative delivery. This increased risk have also be attributed to labour dystocia due to cephalopelvic disproportion commonly seen among obese women as a result of association between maternal obesity and fetal macrosomia[11,12].

However, after adjusting for several confounding factors, 
maternal obesity remains an independent risk factor for caesarean section $[13,14]$. Obesity might create dysfunctional labour independent of true feto-pelvic disproportion. Some researchers however speculated that this risk may be as a consequence of increased soft-tissue deposits of fats in the pelvis of obese women. The soft tissue dystocia in maternal pelvis of obese women may explain the higher risk of caesarean section as more time and stronger uterine contractions are needed for labour to progress $[8,15]$. This may be supported by the fact that maternal fat is accumulated centrally than peripherally during pregnancy especially among obese women [16]. Hence, does the progress of labour differ between obese and non-obese pregnant women? This study was therefore undertaken among obese and non-obese (controls) women who presented in active phase of labour at Bingham University Teaching Hospital Jos, Nigeria to ascertain any relationship between maternal obesity, course of labour and risk of caesarean delivery.

\section{Subjects and Methods}

We performed a retrospective cohort study of 170 obese and 170 non-obese women who presented in active phase of labour (cervical os dilatation of $\geq 4 \mathrm{~cm}$ ) to ascertain labour progression and risk of caesarean section. It is a secondary analysis of women who were previously enrolled in an observational study to assess the impacts of maternal obesity on pregnancy outcomes at Bingham University Teaching Hospital, Jos. Eligibility criteria included singleton pregnancy at 37 weeks' gestation or more, vertex presentation, spontaneous labour, and cervical dilatation of $4 \mathrm{~cm}$ and above. Women that had emergency caesarean delivery after just $\leq 2$ hours in active phase of labour, had augmentation of labour and those that presented in second stage of labour were excluded from the study. Also excluded were women with hypertension, gestational diabetes, previous caesarean section, height less than 1.52 metres and those whose babies' birth weight were $>4 \mathrm{Kg}$. The subjects were matched for age and parity and the proforma for each woman and their obstetric records including the partographs were reviewed and analyzed.

Maternal variables assessed were age, height and weight at booking, gestational age at delivery, mode of delivery, cervical os dilatation at presentation in the labour ward, number of hours taken to attain full cervical dilation $(10 \mathrm{~cm})$. Cervical dilatation rate per hour was calculated by subtracting from 10 $\mathrm{cm}$ the baseline cervical os dilatation on admission in the labour ward divided by the number of hours taken to achieve full cervical dilatation, using the time at admission as the baseline(zero hour).

Body Mass Index (BMI) is used as a universal method of classifying obesity. Maternal body mass index was calculated based on body weight $(\mathrm{Kg})$ divided by height square (metres) at booking during the first trimester. Obese women were those that had BMI of $\geq 30 \mathrm{Kg} / \mathrm{m}^{2}$ while those with normal BMI of $18.5-24.9 \mathrm{Kg} / \mathrm{m}^{2}$ served as non-obese controls. The Human Research and Ethics Committee of the hospital gave approval for the study. Data was analyzed using SPSS version 16 for windows (SPSS Inc., Chicago, IL, USA). Descriptive statistics was done and continuous variables were compared between obese and non-obese women using student $t$-test while categorical variables were compared using Chi-square test. A $P$ value $<0.05$ was considered statistically significant.

\section{Results}

A total of 340 women that fulfilled the inclusion criteria were included in the study, comprising 170 each of obese subjects and non-obese controls. The mean age and parity of the study groups was $30.6 \pm 4.8$ years and $1.9 \pm 1.6$ respectively. There was no statistical difference on the mean age in years $(31.0 \pm 4.3$ versus $30.1 \pm 5.3, \mathrm{P}=0.27)$ and parity $(2.0 \pm 1.6$ versus $1.7 \pm 1.5, \mathrm{P}=0.25)$ between obese women and non-obese controls. The average gestational age at delivery for obese women was $39.1 \pm 1.6$ weeks while that of the controls was $39.9 \pm 1.8$ weeks $(\mathrm{P}=0.30)$. However, there was a statistical difference on the mean weight at delivery between the subjects and the control, with weights of $90.6 \pm$ 15.0 and $72.7 \pm 9.0 \mathrm{Kg}$ respectively $(\mathrm{P}=<0.0001)$. Table 1 shows the combined age and parity distribution of the study populations.

Table 1. Age and parity distribution of the study populations.

\begin{tabular}{lll}
\hline Characteristics & Frequency & Percentage \\
\hline Age groups (Years) & & \\
$\leq 20$ & 5.0 & 1.5 \\
$21-25$ & 55.0 & 16.2 \\
$26-30$ & 147.0 & 43.2 \\
$31-35$ & 100.0 & 29.4 \\
$36-40$ & 28.0 & 8.2 \\
$>40$ & 5.0 & 1.5 \\
Total & 340.0 & 100.0 \\
Parity & & \\
0 & 97.0 & 28.5 \\
$1-4$ & 225.0 & 66.2 \\
$\geq 5$ & 18.0 & 5.3 \\
Total & 340 & 100.0 \\
\hline
\end{tabular}

The mean cervical os dilatation at presentation in active phase of labour was $4.9 \pm 1.8 \mathrm{~cm}$ and $5.0 \pm 1.7 \mathrm{~cm}$ respectively for the obese and non-obese women $(\mathrm{P}=0.64)$. There was no significant statistical difference on the duration of labour (baseline value at presentation to full cervical dilatation) between obese and normal weight women $(7.5 \pm 3.9$ versus $6.2 \pm 3.4$ hours, $\mathrm{P}=0.57)$. However, the mean cervical os dilatation in centimeters per hour between obese and non-obese women was statistically significant $(0.87 \pm 0.4$ versus $1.2 \pm 0.5 \mathrm{~cm}, \mathrm{P}=0.001$ ).

The overall caesarean delivery rate was $16.2 \%(55 / 340)$ while 285 of the women had vaginal delivery $(83.8 \%)$. Caesarean section rates among obese women and non-obese controls were $23.5 \%(40 / 170)$ and $8.8 \%$ (15/170) respectively. Women with obesity had about three times higher risk of having a caesarean delivery compared to the non-obese controls ( $\mathrm{P}=0.002$, OR 3.2, 95\% CI 1.15 - 8.62). In addition, obese women were eleven times more likely to have a 
caesarean delivery as a result of failure to progress in labour compared to normal weight women ( $\mathrm{P}=0.03$, OR $11.0,95 \%$ CI 1.0 - 120.0). There was no statistical difference on the mean birth weight of the babies delivered by obese women and their non-obese counterparts. The average birth weight of the babies were $3.6 \pm \mathrm{Kg} 0.6 \mathrm{Kg}$ and $3.4 \pm 0.5 \mathrm{Kg}$ respectively $(\mathrm{P}=0.06)$. Table 2 shows the indications for caesarean delivery in both study groups.

\section{Discussion}

Despite excluding potential confounding factors and the fact that there was insignificant cervical dilatation at presentation during active phase of labour between the study groups, we observed a significant slower rate of cervical dilatation among obese women compared to non-obese controls. This corroborated findings from previous studies [17 - 19] and this was found even among obese women undergoing induction of labour[20]. This may be due to the accumulating clinical evidences suggesting that obesity has the potential of compromising the intensity or efficiency of uterine contractility. Obesity has been observed to be associated with uterine quiescence or suppression of myometrial activity by both clinical and biochemical markers [21].

Obese women have been noted to have longer gestation and are more likely to deliver beyond 41 weeks' gestation than normal weight women [22,23]. A study by Zhang et al demonstrated that myometrial tissues obtained at caesarean section from obese women contract with less force in vitro as indicated by lower calcium fluxes compared to normal weight women [21]. The reason for this myometrial inhibition has been suggested to be due to biochemical changes induced by obesity as result of elevated leptin and cholesterol levels. Leptin and cholesterol has been shown to have inhibitory effects on myometrial activity and calcium signaling [24,25]. Also, anxiety and stress levels during pregnancy in obese women is higher and the resulting elevated catecholamines may adversely affect uterine activity [26,27]. Hence, the combination of increased risk of post-term pregnancy and inadequate or ineffective uterine contraction patterns in pregnant obese women due to effects of biochemical factors may explain the slower rate of cervical dilation noted among these women in this study.

Many studies found increased duration of first stage of labour among obese women compared to non-obese subjects $[17-21]$. These reports are however contrary to the finding in this study where there was no significant difference between the mean duration of labour between obese women and non-obese controls. Caesarean section rate in this study was noted to be about four times higher among obese than in normal weight women. Therefore, the insignificant relationship between the two study groups in relation to duration of first stage of labour may be attributed to the fact that drop outs due to caesarean delivery before $10 \mathrm{~cm}$ cervical dilatation among obese women probably influenced our finding.

The risk of caesarean section among obese women presenting in active phase of labour was significantly higher compared to normal weight women in this study, despite having the same mean cervical dilatation at presentation and excluding women with confounding variables. This is corroborated by previous studies that showed increased risk of caesarean section among obese women $[8,9,20,28]$. It has also been noted that despite adjusting for confounding factors such as birth weight, maternal obesity remain an independent risk factor for caesarean delivery [21,29].

There was a significant relationship between maternal obesity and caesarean delivery due to failure to progress or labour dystocia in this study. This is in agreement with other studies which reported that prolonged first stage of labour and failure to progress is $2-4$ times more frequent in obese than in non-obese women $[18,19,29]$. Also, Zhang et al reported from a clinical study that obese women had elevated risk of caesarean section mainly due to abnormal progress of labour in the first stage of labour[21]. Several researchers have speculated that added soft-tissue deposits in the pelvis of obese women might narrow its diameter which ultimately predisposes to prolong labour leading to increased risk of abdominal delivery due to failure to progress in labour $[8,15]$. It is possible that combined effects of poor myometrial contractility and obstructive factor due to increased pelvic fat deposits may explain the elevated risk of caesarean section among obese women. However, due to retrospective nature of the study, we can only establish relationship between obesity and progress of labour in its first stage and not causality.

This study has some potential limitations that need to be highlighted. Firstly, it was a retrospective study with a relatively small sample size. Measurement of cervical dilatation was subjective and was based on assessment carried out by several physicians and midwives. Also, we cannot completely state that all confounders were excluded from the study. These include information about fetal factors such as persistent occipito-posterior position that may influence progress of labour and increase the risk of caesarean delivery were lacking. However, this research provides an insight into progress of labour among obese women in our environment as no previous related study to the best of our knowledge has been carried out among women in North-central Nigeria.

\section{Conclusion}

Maternal obesity may interfere with rate of progress of labour among obese women in active phase of labour with associated increased risk of caesarean delivery in our clinical setting. We recommend that a larger prospective study with streamline labour management protocol be carried out especially with respect to objective assessment of uterine activity using intra-uterine pressure catheters in order to substantiate or otherwise the findings from this study. 
Table 2. Indications for caesarean section during the first stage of labour.

\begin{tabular}{|c|c|c|c|c|}
\hline \multirow{2}{*}{ Indications } & \multicolumn{2}{|c|}{ Obese women } & \multicolumn{2}{|c|}{ Non-obese women } \\
\hline & Frequency & Percentage & Frequency & Percentage \\
\hline Failure to progress & 28.0 & 70.0 & 3.0 & 20.0 \\
\hline Suspected fetal distress & 6.0 & 15.0 & 7.0 & 46.7 \\
\hline Obstructed labour & 4.0 & 10.0 & 5.0 & 33.3 \\
\hline Abruptio placentae & 2.0 & 5.0 & 0.0 & 0.0 \\
\hline Total & 40.0 & 100.0 & 15.0 & 100.0 \\
\hline
\end{tabular}

\section{Acknowledgements}

We wish to acknowledge all Resident Doctors, House officers and Midwives in the department for their contributions in meticulous documentation of relevant labour ward information used for this research.

\section{References}

[1] BaetenJM, BukusiEA, Lambe M. Pregnancy complications and outcomes among overweight and obese women. Am J Public Health 2001; 91: 436 - 40 .

[2] Heslehurst N, Simpson H, Ells LJ, Rankin J, Wilkinson J, Lang $\mathrm{R}$, et al. The impact of maternal BMI status on pregnancy outcomes with immediate short-term obstetric resource implications: a meta-analysis. Obes Rev 2008; 9: 635 - 83.

[3] NohrEA, BechBH, Davies MJ, Frydenberg M, Henriksen TB, Olsen J. Prepregnancy obesity and fetal death: a study within the Danish National Birth Cohort. ObstetGynecol 2005; 106: $250-9$.

[4] Ramsay JE, Greer I, Sattar N. ABC of obesity. Obesity and reproduction. BMJ 2006; 333: $1159-62$.

[5] Cogswell ME, Perry GS, Schieve LA, Dietz WH. Obesity in women of childbearing age: risks, prevention, and treatment. Prim Care Update Ob Gyns 2001; 8: 89 - 105.

[6] Kanaglingam MG, Forouhi NG, Greer IA, Sattar N. Changes in booking body mass index over a decade: retrospective analysis from a Glasgow Maternity Hospital. BJOG 2005; 112: 1431 - 3 .

[7] Anzaku AS, Achara AP, Akaba GO, Yakubu EN. Prevalence and Risk Factors for Obesity in a Nigerian Obstetric Population. American Journal of Health Research 2014; 5: $229-233$.

[8] Kaiser PS, Kirby RS. Obesity as a risk factor for cesarean in a low risk population. ObstetGynecol 2001; 97: $39-43$.

[9] Young TK, Woodmansee B. Factors that are associated with cesarean delivery in a large private practice: the importance of prepregnancy body mass index and weight gain. Am J ObstetGynecol 2002; 187: $312-20$.

[10] PerlowJH, Morgan MA, Montgomery D, Towers CV, Porto M. Perinatal outcome in pregnancy complicated by massive obesity. Am J ObstetGynecol 1992; 167: 968-72.

[11] Cedergren MI. Maternal morbid obesity and the risk of adverse pregnancy outcome. ObstetGynecol 2004; 103: 219 24.

[12] Khashan AS, Kenny LC. The effects of maternal body mass index on pregnancy outcome. Eur J Epidemiol 2009; 24: 697 705 .
[13] Roman H, Goffinet F, Hulsey TF, Newman R, RobillardPY, Hulsey TC. Maternal body mass index at delivery and risk of caesarean due to dystocia in low risk pregnancies. ActaObstetGynecol 2008; 87: 163-70.

[14] Sheiner E, Levy A, Menes TS, Silverberg D, Katz M, Mazor M. Maternal obesity as an independent risk factor for caesarean delivery. PaedPerinatEpidemiol 2004; 18: 196-201.

[15] Jensen H, Agger AO, Rasmussen KL. The influence of prepregnancy body mass index on labor complications. ActaObstetGynecolScand 1999; 78: 799 - 802.

[16] Ehrenberg HM, Huston-Presley L, Catalano PM. The influence of obesity and gestational diabetes mellitus on accretion and the distribution of adipose tissue in pregnancy. Am J ObstetGynecol 2003; 189: 944 - 8.

[17] Norman SM, Tuuli MG, Odibo AO, Caughhey AB, Roehl KA, Cahill AG. The effects of obesity on the first stage of labor. ObstetGynecol 2012; 120: 130 - 5 .

[18] Kominiarek MA, Zhang J, van Veldhuisen P, Troendle J, Beaver J, Hibbard JU. Contemporary labour pattern: the impact of maternal body mass index. Am J ObstetGynecol 2011; 205: $244-8$.

[19] Verdiales M, Pacheco C, Cohen WR. The effect of maternal obesity on the course of labor. J Perinat Med 2009; 37: 651 - 5 .

[20] NuthalapatyFS, Rouse DJ, Owen J. The association of maternal weight with cesarean risk, labor duration, and cervical dilatation rate during labour induction. ObstetGynecol 2004; 103: $452-6$.

[21] Zhang J, Bricker L, Wray S, Quenby S. Poor uterine contractility in obese women. Br J ObstetGynaecol 2007; 114: $343-8$.

[22] Caughey AB, Stotland NE, Washington AE, Escobar GJ. Who is at risk for prolonged and postterm pregnancy? Am J ObstetGynecol 2009; 200: 683 - 5.

[23] Denilson FC, Price J, Graham C, Wild S, Liston WA. Maternal obesity, length of gestation, risk of postdates pregnancy and spontaneous onset of labor at term. Br J ObstetGynaecol 2008; 115: $720-5$

[24] Moynihan AT, Hehir MP, GlaveySV, Smith TJ, Morrison JJ. Inhibitory effect of leptin on human uterine contractility in vitro. Am J ObstetGynecol 2006; 196: 504 - 9.

[25] Zhang J, Kendrick A, Quenby S, Wray S. Contactility and calcium signaling of human myometrium are profoundly affected by cholesterol manipulation: implication for labor?ReprodSci 2007: 14: 456 - 66.

[26] Laraia BA, Siege-Riz AM, Dole N, London E. Pregravid weight is associated with prior dietary restraint and psychological factors during pregnancy. Obesity 2009; 17: 550 -8 . 
[27] Lowe NK, Corwin EJ. Proposed biological linkages between obesity, stress and inefficient uterine contractility during labour in humans. Medical Hypothesis 2011; 76: 755 - 60.

[28] Pevzner L, Powers BL, Rayburn WF, Rumney P, Wing DA. Effects of maternal obesity on duration and outcomes of prostaglandin cervical ripening and labor indetion. ObstetGynecol 2009; 114: 1315 - 21.
[29] Cedergren MI. Non-elective caesarean delivery due to ineffective uterine contractility or due to obstructed labour in relation to maternal body mass index. Eur J ObstetGynecolReprodBiol 2009; 145; 163 - 6 . 